Research Paper:

\title{
Nurses' Level of Awareness and Observance of Patients' Rights
}

\author{
Fatemeh Sookhak ${ }^{1}\left[\mathrm{D}\right.$, Mohammad Rafi Bazrafshan ${ }^{1}$, Alireza Ahmadi2 ${ }^{4}\left[\mathrm{D}\right.$, Esmaeil Kavi ${ }^{1}[\mathrm{D}]$
}

1. Department of Nursing, School of Nursing, Larestan University of Medical Sciences, Larestan, Iran.

2. Student Research Committee, Larestan University of Medical Sciences, Larestan, Iran.

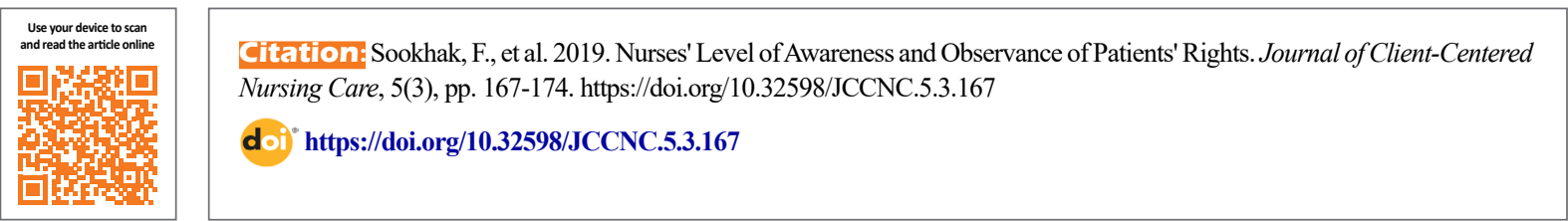

(c) (i) (5)

Article info:

Received: 10 Mar 2019

Accepted: 27 Jun 2019

Published: 01 Aug 2019

Keywords:

Knowledge,

Performance, Nurse,

Patient's rights

\section{A B S T RA C T}

Background: Patient's rights as one of the basic pillars in defining the standards of clinical services indicate that the patient's biopsychosocial and spiritual needs are met in the form of standards, rules, and regulations. This study aimed to evaluate the level of awareness and observance of patients rights by nurses working in hospitals affiliated to Larestan University of Medical Sciences.

Methods: In this descriptive cross-sectional study, 83 clinical nurses were recruited by convenience sampling method. To collect the research data, researcher-made questionnaires, including Patient's Rights Awareness and "Patient's Rights Observance were used. The reliability of the two parts of the questionnaire was reported using Cronbach's alpha coefficients as 0.51 and 0.69 , respectively. The obtained data were analyzed in SPSS using descriptive and Chi-squared tests.

Results: The knowledge of patient rights was poor, moderate, and good in $81.9 \%, 16.9 \%$, and $1.2 \%$ of the nurses, respectively. Additionally, nurses' performance regarding patients' rights was reported as moderate in $83.1 \%$, poor in $13.3 \%$, and good only in $3.6 \%$ of them. Chi-squared test results revealed that among the demographic variables, only gender and education were significantly correlated with the knowledge and practice of nurses regarding the observance of patients' rights $(\mathrm{P}<0.05)$.

Conclusion: The study participants' knowledge of patients' bill of rights was poor, and their observance of patients' rights was moderate; thus, interventions should be performed to prevent the violations of patients' rights. Continuing education programs and in-service training about the observance of the patients' bill of rights should be considered more seriously.

\footnotetext{
* Corresponding Author:

Alireza Ahmadi, BSc.

Address: Student Research Committee, Larestan University of Medical Sciences, Larestan, Iran.

Tel: 98 (910) 7030334

E-mail: saeedahmadi228@yahoo.com
} 


\section{Highlights}

-A descriptive study assessed the level of awareness and observance of patients' rights by nurses working in hospitals;

- Evaluation of the level of awareness and observance of patients' rights by nurses working in hospitals;

- The study participants' knowledge of patients' bill of rights was poor, and their observance of patients' rights was moderate.

\section{Plain Language Summary}

A descriptive cross-sectional study was conducted on 83 nurses working in hospitals. Most patients believe that some of their rights, including information, treatment, and acceptance or rejection of treatment are not followed by healthcare providers. Lack of awareness of the patient's rights may be due to inadequate or inappropriate information regarding the subject of patient's rights. The results of this study revealed that the overall score of nurses' performance about patient's rights was reported as moderate in $83.1 \%$, weak in $13.3 \%$, and good only in $3.6 \%$ of the nurses, which require more attention of the managers of the related hospitals. Some workshops and other solutiono are recommended.

\section{Introduction}

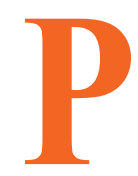

atient's rights are among the main pillars in defining the standards of clinical services. As the attention of international communities to human rights is increased, the concept of patient's rights has been growingly taken into consideration (Nikbakht-Nasrabadi et al. 2015; World-HealthOrganization, 2000). Patient's rights require observing that the biopsychosocial and spiritual needs of the patient are met; these needs have been classified in the form of standards, rules, and regulations; the healthcare team is responsible and obliged to implement and adhere to those (Vaskooei-Eshkevari et al. 2009).

The patient's bill of rights" is advocating the human rights to maintain his sanctity and dignity to ensure that at the time of admission and during medical activities, their body, soul, and health will be well-taken care of without discrimination regarding their age, gender, religion, ethnicity, economic status, and so on (Kent 2014). Therefore, most health systems in most countries have developed and maintained a bill entitled patient's rights"; it is at the disposal of executive levels and is supported by the authorities of hospitals who are required to submit it to the patients when hospitalized until fully acquainted with their rights (Nami Nehad, 2005).

In Iran, the patients' bill of rights was drafted and provided to health centers in 2002, and its text of the amendment was communicated to the relevant centers in 2009 (Parsapoor, Bagheri \& Larijani 2010). Accordingly, some of the patients' rights in this bill include proper and high-quality care and treatment, access to essential and adequate information, right to have a choice and decisionmaking, the confidentiality of patient's information, informed consent provision, the right to independence, the right to having health education, observing the patient's privacy, a peace of mind and death with dignity, and the right to objection, complaint, and compensation, etc. (Hajavi, Tabibi \& Sarbaz 2005; Parsapoor et al. 2009).

A key indicator for assessing the quality of healthcare services is to examine the status of patient rights observance by the healthcare providers and healthcare service recipients (Astaraki \& Hosseini 2015). Besides, the observance of patients' rights is a critical factor in improving and regulating the relationship between the providers and recipients of services; it is naturally of great importance in healthcare system management (Parsapoor et al. 2009). The increasing awareness of communities about health and health issues and the increased costs of healthcare services for the consumers has made patients more likely to care for themselves and follow-up their disease, compared to the past; thus, when their expectations are not fulfilled, they might react to the violation of their basic rights (Almond 2001). Individuals' health information has been improved; they consider hygiene, health, and the productivity of health services as their basic right (Levinsky 1996).

Support is an essential part of nursing. Gadow defines it as helping the patients to recognize their needs, inform them of their rights, and protect these rights and interests (Gadow 1990). Nevertheless, some studies indicated 
that although nurses have a relatively high awareness of the concept of patients' rights, they believe that the observance of such rights needs some essential requirements which encounter this important ethical issue with difficulty (Hooshmand et al. 2007).

Most patients believe that some of their rights, including receiving information regarding diagnosis and treatment, the consequences and risks of acceptance or rejection of treatment, paying attention to their demands and what they say are not followed by healthcare providers (Hooshmand et al. 2007). Generally, there are controversial findings of the level of awareness and observance of patient rights by nurses. A study indicated that patient's rights range from poor to desirable, depending on the definition of right. For example, the highest level of observance of patients' rights belonged to the patient's privacy and respect for their confidentiality, which was reported to be $100 \%$ desirable by all the investigated individuals. However, the lowest value was related to the provision of sufficient information to patients, where only $48.1 \%$ reported it as desirable (Sabzevari et al. 2016). Rohafruz et al. have also reported the Mean \pm SD score of satisfaction with the observance of the charter of patients' rights as $71.6 \pm 18.2$. They also found that $60 \%$ of the patients had a satisfactory moderate level of the observance of their rights charter (Rokhafrooz et al. 2017). The first step in observance of these rights is awareness; thus, it is necessary to explore the nurses' level of knowledge about these rights.

Furthermore, adopting measures to improve nurses' knowledge of patients' rights provides them with better conditions for observing these rights. Besides, understanding the viewpoint and knowledge level of nurses regarding the observance of patients' rights can also be the basis for better observance of these rights (Hooshmand et al. 2007). Additionally, there are structural and cultural differences among the previously studied communities. Accordingly, any policy on developing nurses' performance in the field of observance of patient rights requires an initial assessment and monitoring of the level of awareness and the current level of observance of patient's rights in targeted society. This study aimed to evaluate the level of awareness and observance of patients' rights by nurses.

\section{Materials and Methods}

This descriptive cross-sectional study assessed the level of awareness and observance of patients' rights by nurses working in hospitals affiliated to Larestan University of Medical Sciences. Based on Cochran's sampling formu- la, the minimum sample size with a $95 \%$ confidence level, an acceptable error of 0.05 , and a distribution ratio of $20 \%$, was calculated as 83 nurses. The study participants were selected by convenience sampling method. To collect the required data, a researcher-made questionnaire containing two sections of a patient's rights awareness and patient's rights observance was used. This questionnaire consists of 42 questions which 21 questions evaluated the nurses' awareness of 7 legal components (the right to information and awareness, the right to choose, the right to privacy, the right to respect, the right to refuse, the right to care and appropriate treatment, and the right to complaint) and 21 other questions evaluated the performance of nurses in terms of observing these rights.

In this study, Cronbach's alpha coefficient was obtained as 0.51 for the subscale of the patient's rights awareness and 0.69 for the patient's rights observance subscale. These data indicate moderate and relatively desirable reliability of the research tool. The validity of the questionnaire was confirmed by 10 faculty members of the university. The achieved data were analyzed in SPSS using descriptive tests such as mean, frequency, and percentage, as well as the Chi-squared test.

\section{Results}

Among the study subjects, $10 \%$ were male, and $90 \%$ were female; $67 \%$ were married, and $33 \%$ were single. Furthermore, $96 \%$ had BA, $2.4 \%$ had an MA degree, and $1.6 \%$ had an associate degree. In total, $26 \%$ of the nurses worked in the emergency department, $22 \%$ in the intensive care unit, $8.5 \%$ in the pediatric ward, $8.5 \%$ in the internal ward, and the rest were occupied in other wards. Moreover, $88 \%$ were staff nurses, $9 \%$ were matrons, and $3 \%$ were supervisors. The Mean \pm SD age of the study participants was $30.76 \pm 6.71$ years. Frequency distribution and percentage of nurses' awareness of the patients' bill of rights and its subscales are illustrated in Table 1.

Regarding the performance of nurses concerning patients' rights, except in the area of respect, for which most participants reported good performance with $43.4 \%$; in other areas, nurses had poor to moderate levels of observance of patients' rights. Frequency distribution and percentage of nurses' performance and its subscales are presented in Table 2.

The Chi-squared test results indicated that among the demographic variables, only gender was significantly associated with the nurses' knowledge of patient's rights. The educational level variable also had a significant re- 
Table 1. Frequency distribution and percentage of nurses' awareness of the patients' bill of rights

\begin{tabular}{cccc}
\hline & \multicolumn{2}{c}{ Nurses' Awareness of Patients' Bill of Rights } \\
\cline { 2 - 4 } Patients' Bill of Rights & Weak & Noderate & Good \\
\cline { 2 - 4 } & $54(65.1)$ & $29(34.9)$ & $0(0)$ \\
\hline Information access and awareness & $53(63.9)$ & $28(33.7)$ & $2(2.4)$ \\
\hline Choose & $54(65.1)$ & $26(31.3)$ & $1(3.6)$ \\
\hline Privacy & $74(89.2)$ & $8(9.6)$ & $7(8.4)$ \\
Respect & $65(78.3)$ & $11(13.3)$ & $2(2.4)$ \\
Refuse & $66(79.5)$ & $15(18.1)$ & $10(12)$ \\
\hline Appropriate care and treatment & $73(88)$ & $0(0)$ & $1(1.2)$ \\
\hline Complaint & $68(81.9)$ & $14(16.9)$ & \\
\hline
\end{tabular}

Client- Centered Nursing Care

Table 2. Frequency distribution and percentage of nurses' performance in the aspects of observance of the patients' bill of rights

\begin{tabular}{cccc|}
\hline \multirow{2}{*}{\begin{tabular}{c} 
Patients' Bill of Rights \\
\cline { 2 - 3 }
\end{tabular}} & \multicolumn{2}{c|}{ Nurses' Performance Regarding Patients' Bill of Rights } \\
\cline { 2 - 4 } & Weak & No. (\%) & Gooderate \\
\hline Information access and awareness & $39(47)$ & $34(41)$ & $10(12)$ \\
\hline Choose & $41(49.4)$ & $35(42.2)$ & $7(8.4)$ \\
\hline Privacy & $13(15.7)$ & $51(61.4)$ & $19(22.9)$ \\
\hline Respect & $21(25.3)$ & $26(31.3)$ & $36(43.4)$ \\
Refuse & $23(27.7)$ & $52(62.7)$ & $8(9.6)$ \\
\hline Appropriate care and treatment & $77(92.8)$ & $6(7.7)$ & $0(0)$ \\
\hline Complaint & $51(61.4)$ & $0(0)$ & $32(38.6)$ \\
\hline
\end{tabular}

lationship with the nurses' performance in observing patients' rights $(\mathrm{P}<0.05)$ (Tables $3 \& 4)$.

\section{Discussion}

This descriptive cross-sectional study was conducted on 83 nurses working in hospitals affiliated to Larestan University of Medical Sciences. According to the study results, the knowledge of the majority of nurses $(81.9 \%)$ regarding patient's rights was weak, $16.9 \%$ of them had moderate, and only $1.2 \%$ had good knowledge in this respect. Thus, the knowledge and awareness of nurses about the rights of patients are undesirable. This finding is consistent with those of some studies (Parsinia, Goodarzi, \& Babaei 2007; Aghighi et al. 2014 ; Hakan Özdemir et al. 2009; Halawany et al. 2016). However, this finding was inconsistent with those of Salehi Vaziri and Sadeghi. They argued that nurses had a high level of awareness (Salehi Vaziri \& Sadeghi, 2015). Ghaljeh et al. reported the mean score of nurses' knowledge as 45.13, which was moderate (Ghaljeh et al. 2010). Nasiriany et al. also described the nurses' awareness of patients' rights to be well (Nasiriany et al. 2002). Furthermore, KhodaMoradi et al. reported that the knowledge of $82.3 \%$ of nursing trainees about patient's rights was good (KhodaMoradi et al. 2010), which was inconsistent with the present findings. 
Table 3. Relationship between nurses' knowledge about patient rights and their demographic characteristics

\begin{tabular}{|c|c|c|c|c|c|c|c|}
\hline \multicolumn{2}{|c|}{$\begin{array}{l}\text { Nurses' awareness of the } \\
\text { Patients' Bill of Rights }\end{array}$} & \multicolumn{3}{|c|}{ No. (\%) } & \multirow{2}{*}{$\begin{array}{c}\text { Chi- } \\
\text { squared }\end{array}$} & \multirow[t]{2}{*}{ df } & \multirow[t]{2}{*}{$\mathbf{P}$} \\
\hline Demogra & hic Variables & Weak & Moderate & Good & & & \\
\hline \multirow{2}{*}{ Gender } & Male & $8(9.63)$ & $2(2.4)$ & $1(1.2)$ & \multirow{2}{*}{6.68} & \multirow{2}{*}{2} & \multirow{2}{*}{0.035} \\
\hline & Female & 60 (72.28) & $12(14.45)$ & $0(0)$ & & & \\
\hline \multirow{2}{*}{$\begin{array}{l}\text { Marital } \\
\text { status }\end{array}$} & Married & $44(53.01)$ & 9 (10.84) & $0(0)$ & \multirow{2}{*}{2.19} & \multirow{2}{*}{4} & \multirow{2}{*}{0.7} \\
\hline & Single & $22(26.5)$ & $5(6.02)$ & $1(1.2)$ & & & \\
\hline \multirow{3}{*}{$\begin{array}{l}\text { Educational } \\
\text { level }\end{array}$} & $\begin{array}{l}\text { Associate } \\
\text { degree }\end{array}$ & $1(1.2)$ & $0(0)$ & $0(0)$ & \multirow{3}{*}{1.81} & \multirow{3}{*}{4} & \multirow{3}{*}{0.769} \\
\hline & BA & 66 (79.51) & $13(15.66)$ & $1(1.2)$ & & & \\
\hline & MA & $1(1.2)$ & $1(1.2)$ & $0(0)$ & & & \\
\hline \multirow{10}{*}{ Work place } & Emergency & $14(16.86)$ & $7(8.43)$ & $1(1.2)$ & \multirow{10}{*}{14.7} & \multirow{10}{*}{18} & \multirow{10}{*}{0.682} \\
\hline & pediatrics & $5(6.02)$ & $2(2.4)$ & $0(0)$ & & & \\
\hline & Surgery & $2(2.4)$ & $1(1.2)$ & $0(0)$ & & & \\
\hline & Internal & $7(8.43)$ & $0(0)$ & $0(0)$ & & & \\
\hline & Maternity & $4(4.81)$ & $1(1.2)$ & $0(0)$ & & & \\
\hline & $\begin{array}{l}\text { Gynecology and } \\
\text { Obstetrics }\end{array}$ & $3(3.61)$ & $0(0)$ & $0(0)$ & & & \\
\hline & Intensive care & $18(21.68)$ & $0(0)$ & $0(0)$ & & & \\
\hline & Nurse office & $2(2.4)$ & $0(0)$ & $0(0)$ & & & \\
\hline & Dialysis & $2(2.4)$ & $1(1.2)$ & $0(0)$ & & & \\
\hline & Other & $11(13.25)$ & $2(2.4)$ & $0(0)$ & & & \\
\hline \multirow{3}{*}{ Job position } & Staff & $59(71.08)$ & $13(15.66)$ & $1(1.2)$ & \multirow{3}{*}{0.931} & \multirow{3}{*}{4} & \multirow{3}{*}{0.85} \\
\hline & Matron & $6(7.22)$ & $1(1.2)$ & $0(0)$ & & & \\
\hline & Supervisor & $3(3.61)$ & $0(0)$ & $0(0)$ & & & \\
\hline
\end{tabular}

Client- Centered Nursing Care

Contradictory results regarding the level of nurses' awareness of patient rights were expected because it could be influenced by the sociocultural characteristics of target communities and the training provided to nurses. In addition, the lack of awareness of the patient's rights by some participants may be due to inadequate or inappropriate information regarding the subject of patient's rights (Halawany et al. 2016). Accordingly, considering that a key nursing principle is respect for human rights and rewarding the patients' dignity, nurses are among the leading pillars of the avocation of patients' rights in hospitals; the awareness of patients' bill of rights and the provision of conditions for healthcare providers to comply with these rights are essential. Therefore, healthcare providers, including nurses, should be aware of the rights of patients and increase their level of knowledge of the patients' bill of rights. Besides, it is imperative that hospital managers take measures to enforce patients' rights and eliminate the existing gap by holding related workshops (Ghaljeh et al. 2010).
Additionally, the obtained results revealed that the overall score of nurses' performance about patient's rights was reported as moderate in $83.1 \%$, weak in $13.3 \%$, and good only in $3.6 \%$ of the nurses. This finding was consistent with that of another study (Pishgar et al. 2015). Besides, in one other study, the rate of observance of patient's rights was moderate in $79 \%$ of the cases (Rashidi, Foroughan \& Hosseini 2012). Poor observance of patients' rights was reported in a hospital in Esfahan, Iran (Mosadegh-Rad, Mohammd \& Esna Ashari 2004). In other words, patients, like other human beings, have vital needs that fail to fully meet some of them due to illness and require other's help. Therefore, with the awareness of the patients' needs, they can be better understood, and more appropriate ways could be selected to assist them. Understanding these needs is a useful framework for providing care. Thus, if the healthcare team, including nurses, are not well aware of the needs of patients and how they are satisfied, they fail to observe the patient's human rights (Mosadegh-Rad, Mohammd \& Esna Ashari 2004). The nurses of hospitals affiliated with Larestan University of Medical Sciences had poor knowledge of 
Table 4. Relationship between nurses' performance about patient rights and their demographic characteristics

\begin{tabular}{|c|c|c|c|c|c|c|c|}
\hline \multirow{2}{*}{\multicolumn{2}{|c|}{$\begin{array}{c}\text { Nurses' Performance Regarding } \\
\text { the Patients' Bill of Rights } \\
\text { Demographic Variables }\end{array}$}} & \multicolumn{3}{|c|}{ No. (\%) } & \multirow{2}{*}{$\begin{array}{c}\text { Chi- } \\
\text { squared }\end{array}$} & \multirow[t]{2}{*}{ df } & \multirow[t]{2}{*}{$\mathbf{P}$} \\
\hline & & Weak & Moderate & Good & & & \\
\hline \multirow{2}{*}{ Gender } & Male & $3(3.61)$ & $7(8.43)$ & $1(1.2)$ & \multirow{2}{*}{3.51} & \multirow{2}{*}{2} & \multirow{2}{*}{0.173} \\
\hline & Woman & $8(9.63)$ & 62 (74.69) & $2(2.4)$ & & & \\
\hline \multirow{2}{*}{$\begin{array}{l}\text { Marital } \\
\text { status }\end{array}$} & Married & $7(8.43)$ & $44(53.01)$ & $2(2.4)$ & \multirow{2}{*}{0.228} & \multirow{2}{*}{4} & \multirow{2}{*}{0.994} \\
\hline & Single & $4(4.81)$ & $23(27.71)$ & $1(1.2)$ & & & \\
\hline \multirow{3}{*}{$\begin{array}{l}\text { Educational } \\
\text { level }\end{array}$} & Associate degree & $0(0)$ & $0(0)$ & $1(1.2)$ & \multirow{3}{*}{40.36} & \multirow{3}{*}{4} & \multirow{3}{*}{0.000} \\
\hline & BA & $9(10.84)$ & $69(83.13)$ & $2(2.4)$ & & & \\
\hline & MA & $2(2.4)$ & $0(0)$ & $0(0)$ & & & \\
\hline \multirow{10}{*}{ Work place } & Emergency & $2(2.4)$ & $18(21.68)$ & $2(2.4)$ & \multirow{10}{*}{10.01} & \multirow{10}{*}{18} & \multirow{10}{*}{0.931} \\
\hline & pediatrics & $2(2.4)$ & $5(6.02)$ & $0(0)$ & & & \\
\hline & Surgery & $0(0)$ & $3(3.61)$ & $0(0)$ & & & \\
\hline & Internal & $2(2.4)$ & $5(6.02)$ & $0(0)$ & & & \\
\hline & Maternity & $1(1.2)$ & $4(4.81)$ & $0(0)$ & & & \\
\hline & $\begin{array}{l}\text { Gynecology and } \\
\text { Obstetrics }\end{array}$ & $0(0)$ & $3(3.61)$ & $0(0)$ & & & \\
\hline & Intensive care & $1(1.2)$ & $16(19.27)$ & $1(1.2)$ & & & \\
\hline & Nurse office & $0(0)$ & $2(2.4)$ & $0(0)$ & & & \\
\hline & Dialysis & $1(1.2)$ & $2(2.4)$ & $0(0)$ & & & \\
\hline & Other & $2(2.4)$ & $11(13.25)$ & $0(0)$ & & & \\
\hline \multirow{3}{*}{ Job position } & Staff & $11(13.25)$ & $59(71.08)$ & $3(3.61)$ & \multirow{3}{*}{2.3} & \multirow{3}{*}{4} & \multirow{3}{*}{0.68} \\
\hline & Matron & $0(0)$ & $7(8.43)$ & $0(0)$ & & & \\
\hline & Supervisor & $0(0)$ & $3(3.61)$ & $0(0)$ & & & \\
\hline
\end{tabular}

Client- Centered Nursing Care

the patients' rights charter, and consequently, on average, have been able to comply with patients' rights; to prevent violations of patient rights in healthcare activities, there is an urgent need to eliminate this issue. Furthermore, the observance of patients' bill of rights should be considered more seriously in continuing education programs and inservice training for implementing the educational needs of nurses. Moreover, the observance of these rights in practice requires many other needs; thus, these requirements should be identified by the hospital administrators, and the necessary measures be taken to resolve them.

According to the study findings, gender and education were key variables to be significantly correlated with the awareness and observance of patients' rights by nurses. This result was in line with that of another study (Parsinia, Goodarzi \& Babaei 2007). In addition, Rashidi suggested a positive and significant relationship between the patient's rights and the level of education; the level of awareness and observance was related to the gender of nurses (Rashidi, Foroughan \& Hosseini 2012).
Nurses' performance and their awareness were found to be undesirable in this study, which requires more attention from the managers of the related hospitals. Conducting interventional research studies to investigate the effect of workshops and other means of education on these variables is recommended.

\section{Ethical Considerations}

\section{Compliance with ethical guidelines}

This study was approved by Larestan University of Medical Sciences with a Code of Ethics in Medical Research of IR.LARUMS.1396.2. Written consent was obtained from the nurses, they were free to refuse to continue the study, and confidentiality of all their personal information was confirmed.

\section{Funding}

This research was financially funded by Larestan University of Medical Sciences. 


\section{Authors' contributions}

All authors contributed equally in preparing all parts of the research.

\section{Conflict of interest}

The authors declared no conflicts of interest.

\section{References}

Aghighi, A., et al. 2014. [Evaluation of patients' knowledge of their rights at military hospital (Persian)]. Journal of Nurse and Physician Within War, 23(24), 24-8.

Almond, P., 2001. What is consumerism and has it had an impact on health visiting provision? A literature review. Journal of Advanced Nursing, 35(6), 893-901. [DOI:10.1046/j.13652648.2001.01932.x] [PMID]

Astaraki, P. \& Hosseini, N., 2015. [Evaluation of respect for patient's rights from the viewpoint of hospitalized patinents in Shohada Ashayer hospital of Khorramabad City in 2013-2014 (Persian)]. Yafte, 17(1), pp. 5-14

Gadow, S. (1990). Existential advocacy: Philosophical foundation of nursing. National League for Nursing publication, (202294):41-51. [PMID]

Ghaljeh, M., et al. 2010. [Physicians and nurses awareness and function about patients' right charter in Zahedan (Persian)]. Journal of Medical Ethics and History of Medicine, 3(5), 69-75.

Hajavi, A., Tabibi, S., \& Sarbaz, Z. M., 2005. [A comparative review of patient's bill of rights in selected countries and proposing a proper solution for Iran (Persian)]. Iranian Journal of Forensic Medicine, 10(36), pp. 196-201.

Hakan Özdemir, M., et al. 2009. Midwives and nurses awareness of patients' rights. Midwifery, 25(6), 756-65. [DOI:10.1016/j. midw.2008.01.010] [PMID]

Halawany, H. S., et al. 2016. Awareness, availability and perception of implementation of patients' rights in Riyadh, Saudi Arabia. The Saudi Journal for Dental Research, 7(2), 132-7. [DOI:10.1016/j.sjdr.2016.04.003]

Hooshmand, A., et al. 2007. [Nurses' information and their view points about patient's rights and practical facilitators in clinics (Persian)]. Hayat, 12(4), 57-66.

Kent, A., 2014. Encyclopedia of library and information science: Volume 35. Boca Raton, Florida: CRC Press. [DOI:10.1201/9781498710459]

KhodaMoradi, K., et al. 2010. [A Survey on knowledge of baccalaureate and master degree nursing students of patient rights (Persian)]. Medical Ethics Journal, 4(12), 133-48.

Levinsky, N. G., 1996. Social, institutional, and economic barriers to the exercise of patients' rights. The New England Journal of Medicine, 334(8), pp. 532-4. [DOI:10.1056/ NEJM199602223340812] [PMID]
Mosadegh Rad, M., Mohammd, A. \& Esna Ashari, P., 2004. [Patients and physicians awareness of patients' rights and its implementation at Beheshti hospital in Isfahan (Persian)]. Iranian Journal of Medical Education, 4(1), 45-54.

Nasiriany, K., et al. 2002. [How nurses respect patient's rights (Persian)]. Iran Journal of Nursing, 15(32), 8-14.

Nikbakht_Nasrabadi, A., et al. 2015. [Effect of nursing ethics workshop on the rights of patients in the emergency department (Persian)]. Cardiovascular Nursing Journal, 4(3), 6-15.

Parsapoor, A., Bagheri, A. \& Larijani, B., 2010. [Review of revolution of patient's right charter (Persian)]. Iranian Journal of Medical Ethics and History of Medicine, 3(Supplement), 39-47.

Parsapoor, A., et al. 2009. [The necessity of observing patients' right: Surveying patients', physicians' and nurses' attitudes around it (Persian)]. Journal of Medical Ethics and History of Medicine, 2(4), 79-90.

Parsinia, M., Goodarzi, M. \& Babaei, G., 2007. [Survey of knowledge of nurses working in hospitals of Karaj City from patient rights (Persian)]. Journal of Nursing and Midwifery Urmia University of Medical Sciences, 5(2), 2-6.

Pishgar, Z., et al. 2015. [Recognizing and respect for patients' rights by operating room personnel of hospitals affiliated with Jahrom University of Medical Sciences (Persian)]. Journal of Education and Ethics in Nursing, 4(3), 49-56.

Rashidi, V., Foroughan, M. \& Hosseini, M., 2012. [The relationship between knowledge and observance of patients' rights in rehabilitation centers of Tehran (Persian)]. Journal of Sabzevar University of Medical Sciences, 11(3), 296-303.

Rokhafrooz, D., et al. 2017. Assessing nurses' moral distress and patients' satisfaction with the observance of the patients' rights charter. Journal of Nursing and Midwifery Sciences, 4(4), 147-53. [DOI:10.4103/JNMS.JNMS_1_18]

Sabzevari, A., et al. 2016. Evaluation of patients' rights observance according to patients' rights charter in educational hospitals affiliated to Mashhad University of Medical Sciences: Medical staffs' views. Electronic Physician, 8(10), 3102-9. [DOI:10.19082/3102] [PMID] [PMCID]

Salehi Vaziri, A. \& Sadeghi, M., 2015. [Comparison of nurses' and paramedics' knowledge of Dr Mir Hosseini Hospital and 576 Shiraz Army on Patient charter of rights in year 2015 (Persian)] Paramedical Sciences and Military Health, 9(2), 28-32.

Vaskooei Eshkevari, K., et al. 2009. [The assessment of observing patients' right in Tehran University of Medical Sciences' hospitals (Persian)]. Journal of Medical Ethics and History of Medicine, 2(4), 47-54.

World Health Organization., 2000. Patients' rights and citizens' empowerment: Through visions to reality: Joint consultation between the WHO Regional Office for Europe, the Nordic Council of Ministers and the Nordic School of Public Health, Copenhagen, Denmark 22-23 April 1999. Copenhagen: WHO Regional Office for Europe. 
This Page Intentionally Left Blank 